\title{
Author Correction: KDM3 epigenetically controls tumorigenic potentials of human colorectal cancer stem cells through Wnt/ $\beta$-catenin signalling
}

\author{
Jiong $\mathrm{Li}^{1 \star}$, Bo Yu${ }^{1}$, Peng Deng ${ }^{1}$, Yingduan Cheng ${ }^{1}$, Yongxin $\mathrm{Yu}^{1}$, Kareena Kevork ${ }^{1}$, Sivakumar Ramadoss ${ }^{1}$, \\ Xiangming Ding ${ }^{2}$, Xinmin $\mathrm{Li}^{2} \&$ Cun-Yu Wang ${ }^{1,3 *}$
}

Correction to: Nature Communications https://doi.org/10.1038/ncomms15146, published online 25 April 2017.

This Article contains errors in Figure 4 and Supplementary Figure 3. In Figure $4 \mathrm{~b}$, the image representing $\mathrm{ALDH}^{-} / \mathrm{EpCAM}^{+}$Control siRNA was taken from the $\mathrm{ALDH}^{+} / \mathrm{EpCAM}^{+} \mathrm{KDM} 3 \mathrm{~A}+\mathrm{B}$ siRNA image. In Supplementary Figure 3b, the image representing $\mathrm{CD}_{133^{+} /}$ $\mathrm{EpCAM}^{+}$was taken from $\mathrm{CD} 133^{+} / \mathrm{EpCAM}^{+}$Control siRNA image of panel a. The correct versions of Figure 4 and Supplementary Figure 3 are shown below. The error has not been corrected in the PDF or HTML versions of the Article.

Published online: 04 November 2019

\begin{abstract}
(c) (i) Open Access This article is licensed under a Creative Commons Attribution 4.0 International License, which permits use, sharing, adaptation, distribution and ce reproduction in any medium or format, as long as you give appropriate credit to the original author(s) and the source, provide a link to the Creative Commons license, and indicate if changes were made. The images or other third party material in this article are included in the article's Creative Commons license, unless indicated otherwise in a credit line to the material. If material is not included in the article's Creative Commons license and your intended use is not permitted by statutory regulation or exceeds the permitted use, you will need to obtain permission directly from the copyright holder. To view a copy of this license, visit http://creativecommons.org/licenses/by/4.0/.
\end{abstract}

() The Author(s) 2019

\footnotetext{
${ }^{1}$ Laboratory of Molecular Signaling, Division of Oral Biology and Medicine, School of Dentistry and Broad Stem Cell Research Center, UCLA, Los Angeles, California 90095, USA. ${ }^{2}$ Department of Pathology and Laboratory Medicine, David Geffen School of Medicine, UCLA, Los Angeles, California 90095, USA.

${ }^{3}$ Department of Bioengineering, Henry Samueli School of Engineering and Applied Science, UCLA, Los Angeles, California 90095, USA.

*email: jli@dentistry.ucla.edu; cunywang@ucla.edu
} 


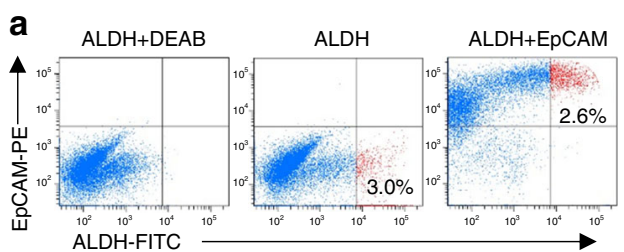

b

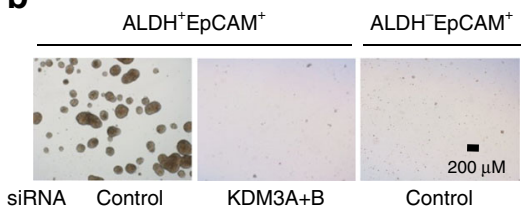

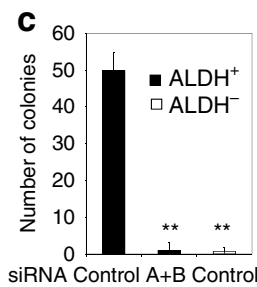

siRNA Control A+B Control d

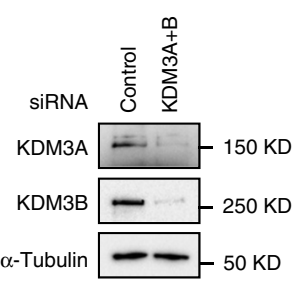

h
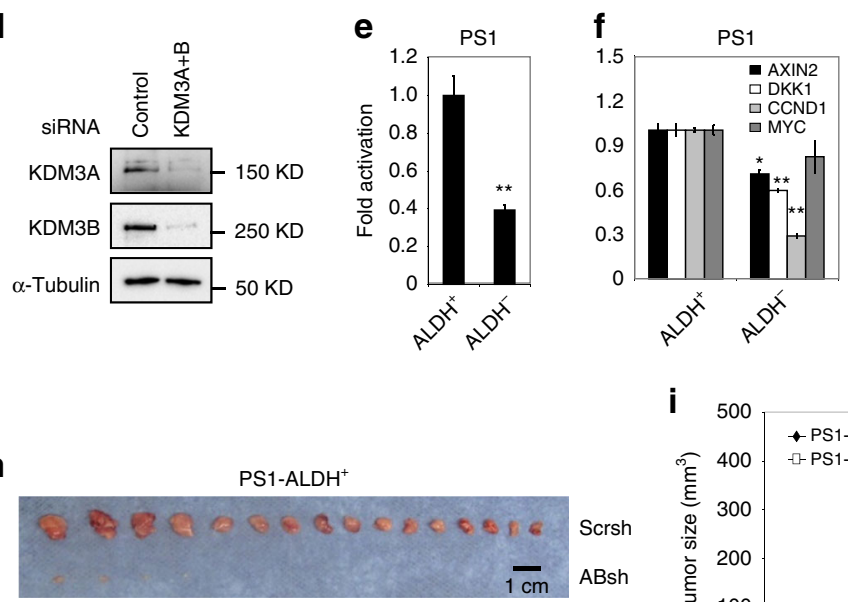

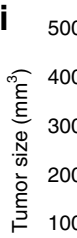

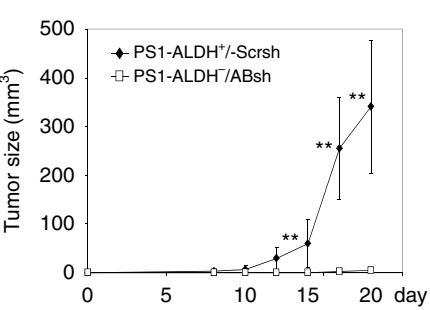

I

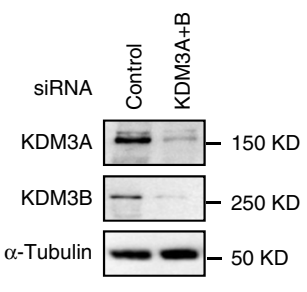

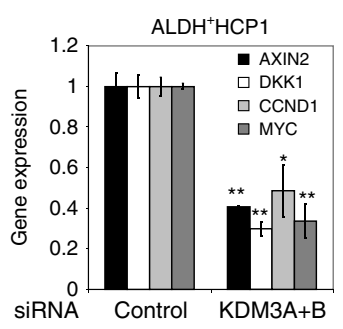

m
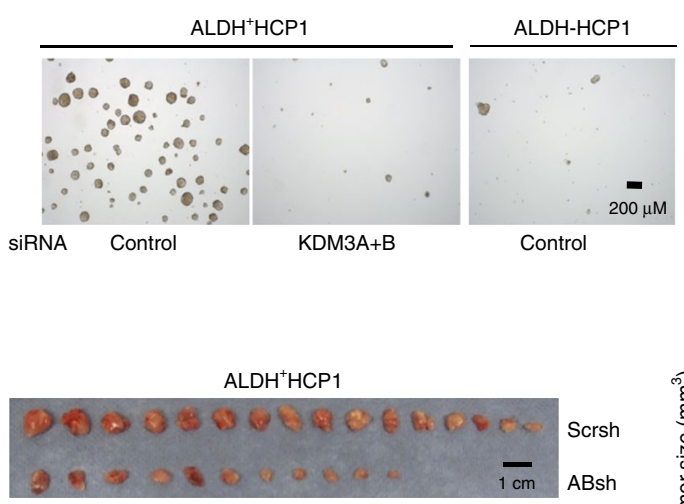
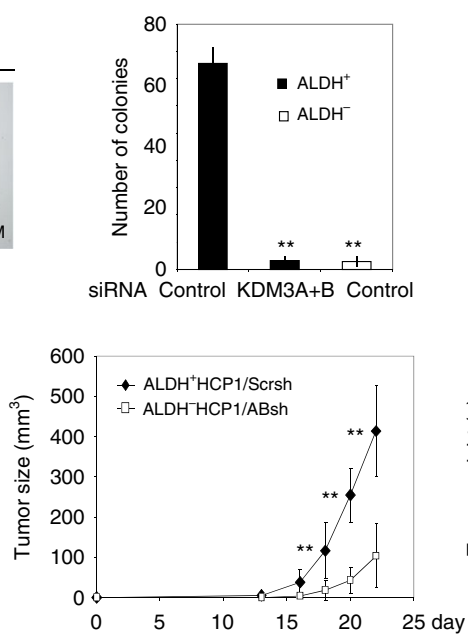

Fig. 4 

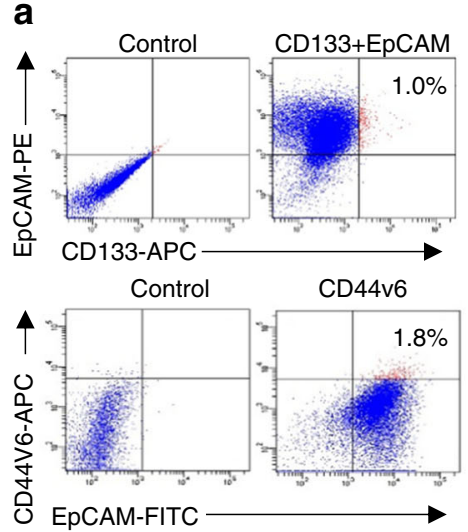

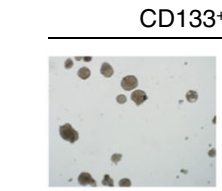

siRNA Control KDM3A+KDM3B

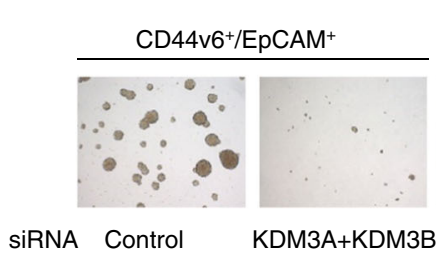
CD44v6-/EpCAM+

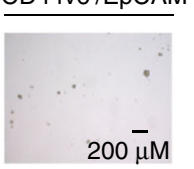

Control

b Patient case 1
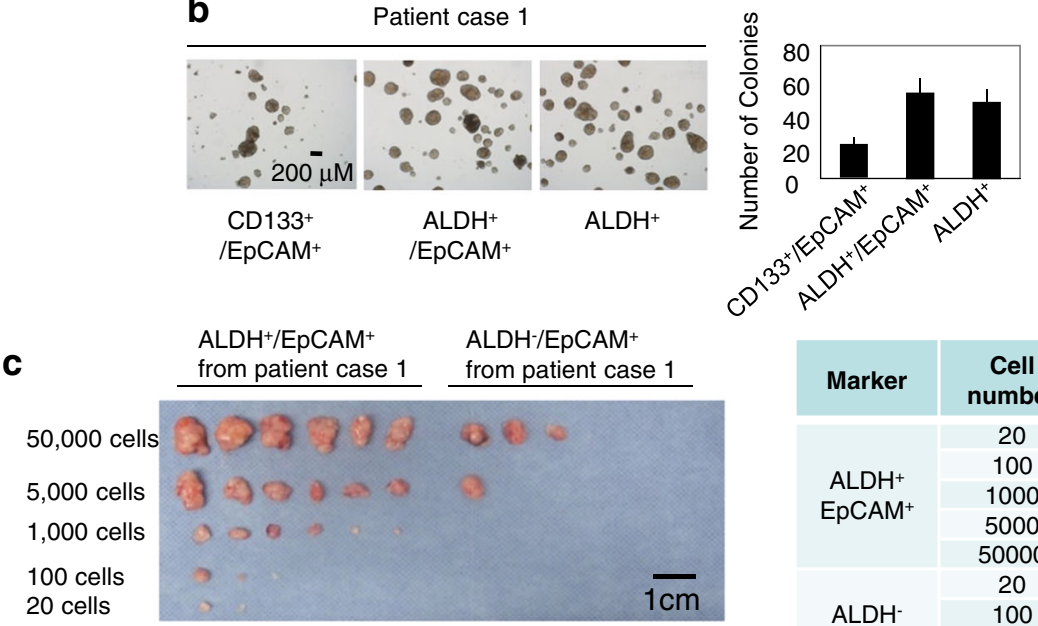

$\mathrm{ALDH}^{+} \mathrm{EpCAM}^{+}$from patient case 1

\begin{tabular}{|c|c|c|}
\hline Marker & $\begin{array}{c}\text { Cell } \\
\text { number }\end{array}$ & $\begin{array}{c}\text { Tumor } \\
\text { frequency }\end{array}$ \\
\hline & 20 & $2 / 6$ \\
\hline ALDH $^{+}$ & 100 & $3 / 6$ \\
ECCAM $^{+}$ & 1000 & $6 / 6$ \\
& 5000 & $6 / 6$ \\
& 50000 & $6 / 6$ \\
\hline ALDH $^{-}$ & 20 & $0 / 6$ \\
ECCAM $^{+}$ & 100 & $0 / 6$ \\
& 1000 & $0 / 6$ \\
& 5000 & $1 / 6$ \\
\hline
\end{tabular}

d
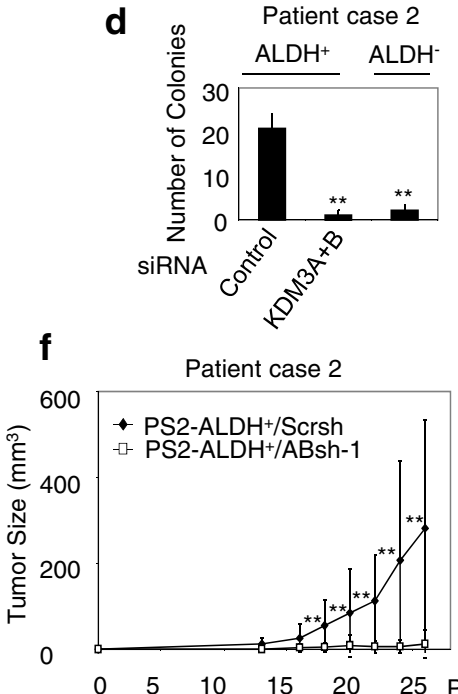

g

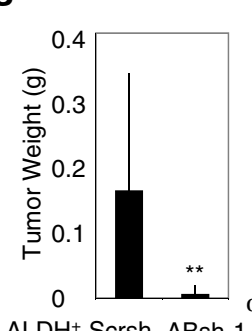

\section{e}

$\mathrm{ALDH}^{+} / \mathrm{Scrsh}$

ALDH+/KDM3ABsh1

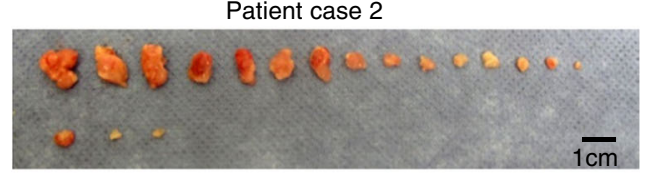

h

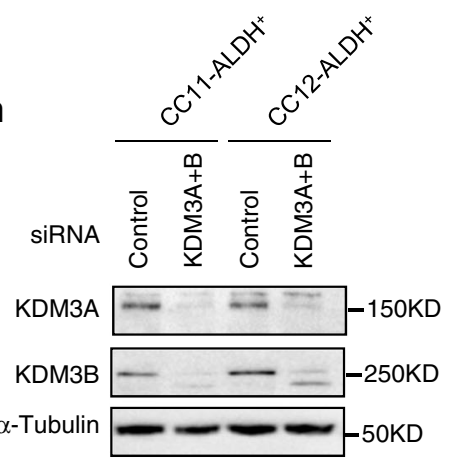

i $\mathrm{CC}_{11-\mathrm{ALDH}^{+}} \mathrm{CC} 11-\mathrm{ALDH}^{-}$

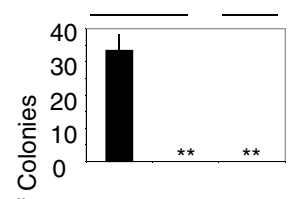

¿ $\mathrm{CC}_{12}-\mathrm{ALDH}^{+} \mathrm{CC12-ALDH}{ }^{-}$

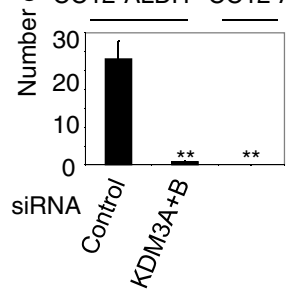

Supplementary Fig. 3 